\title{
Being the younger child in a large African Family: a study of birth order as a risk factor for poor health using the demographic and health surveys for 18 countries
}

Embry M. Howell ${ }^{1 *}$, Nikhil Holla ${ }^{2}$ and Timothy Waidmann ${ }^{1}$

\begin{abstract}
Background: One hundred eighty six nations have adopted 17 Sustainable Development Goals (SDGs), one of which, SDG 3.2, aims to reduce under-5 mortality to 25 deaths per thousand in all countries by 2030. Achieving this goal is daunting for many African countries, where child mortality remains high. Research around the world and over time has shown an association between birth order and mortality, with later born children (of higher "birth order") generally having higher mortality, in addition to having less education and fewer health services. We aim to investigate how child mortality and nutritional status vary by birth order in Africa.

Methods: We obtained data from the Demographic and Health Surveys (DHS) from 18 African countries, one survey in each of the following decades: 1986-1995, 1996-2005, and 2006-2015. We examined mortality for two groups: ages $1-4$ and $5-14$, using a Cox proportional hazards model. We then examined 4 separate nutritional outcomes for young children using logistic regression. Nutritional outcomes are stunting, low weight, consuming fewer than 4 food groups in the past $24 \mathrm{~h}$, and consuming any fruits or vegetables in that period. Analyses control for country and characteristics of the household, mother, and child.

Results: Birth order is significantly related to mortality for both age groups. On average, there is a $13 \%$ increase in mortality risk for each increase in birth order for children ages 1-4, and a $10 \%$ increase in children ages 5-14. Similarly, we find that a higher birth order child is significantly more likely to be stunted (OR 1.08) or of low weight (OR 1.06). Higher birth order children are significantly more likely to consume fewer food groups (OR 1.11) and less often eat fruits and vegetables (OR 1.09).

Conclusion: Birth order is significantly related to mortality and nutritional status in large African families, with later born children having poorer outcomes. These data suggest that increased attention to family planning initiatives and targeted nutritional interventions provide clear strategies for meeting the child mortality and nutritional status Sustainable Development Goals in African countries.
\end{abstract}

Keywords: Child health, Global health, Nutrition

\footnotetext{
* Correspondence: ehowell@urban.org

${ }^{1}$ The Urban Institute, 2100 M Street NW, Washington, DC, USA

Full list of author information is available at the end of the article
} 


\section{Background}

In 2000 the United Nations developed eight Millennium Development Goals (MDGs) [1]. One of these-Millennium Development Goal (MDG) 4-committed to reducing worldwide mortality among children under 5 years of age by $2 / 3$ by 2015 . While the goal was not met, under- 5 mortality fell from 90.6 per thousand live births in 2000 to 42.5 per thousand in 2015 [2]. Moving forward, 186 nations adopted 17 Sustainable Development Goals (SDGs), one of which, SDG 3.2, aims to reduce under-5 mortality to 25 deaths per thousand in all countries by 2030 [3].

Achieving this goal is daunting for many African countries, where child mortality remains high. While African countries have adopted many new initiatives to reduce child mortality [4], an analysis by UNICEF concludes that dozens of African countries will fall short of reaching the child mortality goal on their current path [2].

Countries also adopted SDG 3.7, a commitment to increased access to family planning. In Africa, many women do not practice modern contraception and fertility remains high [5]. In larger families, particularly poor families, as children are added to the household there is increased competition among the children for limited resources such as food, education, and health services. It is possible that meeting SDG 3.7 will have the secondary benefit of improvements in child mortality.

Research around the world and over time has shown an association between birth order and mortality [6-9], with later born children (of higher "birth order") generally having higher mortality. A study of child mortality and nutrition in 45 countries (27 in Africa) in 20062012 shows an adjusted relative risk of mortality of 1.07 for birth orders 3-4 (compared to birth orders 1-2); 1.15 for birth orders 5-6; and 1.28 for birth orders 7+ [10]. Smaller studies in Cambodia and Nigeria also show a disadvantage in child mortality for fourth and higher order births $[11,12]$. Finally, a recent study shows birth order effects to be concentrated among high fertility mothers, those with more than four children [13].

Higher birth order children also have been shown to have less education [14] and fewer health services [15]. In terms of access to food, the multi-country study of birth order in 45 countries cited earlier reports a significant association between birth order and "stunting" (height for age), but not in "low weight" (weight for age) [10]. Studies in Cambodia [11] and the Philippines [16] also show an association between birth order and stunting.

In summary, studies conducted over several decades suggest that being a later born child in a large family may put a child at risk for poor health. This current study contributes substantially to the literature on this important topic by focusing specifically on Africa where both child mortality and lifetime fertility remain high.

\section{Methods}

Data

The paper uses data from the nationally representative Demographic and Health Surveys (DHS) [17] conducted in over 90 developing countries around the world, with sponsorship of the countries themselves and international donors such as USAID. The surveys have been conducted with varying periodicity since 1985 . There is a common questionnaire which countries can augment, leading to substantial cross-country comparability. There have been 6 "phases" of the survey, with each subsequent phase adding new questions and making slight modifications to existing ones.

Our study uses data from 18 African countries (see Table 1). These countries are chosen because they all had at least one DHS survey in each of three decades (1985-1994; 1995-2004; 2005-2014). Data are included from one survey in each decade per country; when the country conducted more than one we chose the survey nearest the mid-point of the decade.

\section{Study countries}

Study countries are broadly representative of Africa regionally, with 8 countries in the west, 5 in the south, 4 in the east, and one in the north (Egypt). The countries contain about half the population of Africa, with two study countries (Egypt and Nigeria) having about a fourth. Population sizes (2015) range from 2.3 million (Namibia) to 184.3 million (Nigeria) [18]. Their GDPs (PPP\$,2013) range from $\$ 748$ (Malawi) to $\$ 10,160$ (Egypt) [19]. Average healthy life expectancy (2013) varies substantially from a high of 60.4 years for males/62.9 for females (Egypt), to a low of 46.6 and 49.3 respectively (Zimbabwe) [20]. Much of this mortality variation is due to the varied rate of HIV prevalence in African countries, from a low of less than .1\% (Egypt, 2014) to a high of $16.7 \%$ (Zimbabwe); the higher prevalence is concentrated in southern and eastern African countries [21]. Lifetime fertility also varies substantially by country, from 3.5 in Egypt to 7.6 in Niger, as does the percentage of married women practicing modern contraception [5]. Similarly, and most pertinent to this study, under-5 mortality varies across the continent and among study countries, ranging from 24 per 1000 live births (Egypt, 2015) to 115 (Mali). Under-5 mortality declined in all 18 countries between 2000 and 2015, but the annual rate of decline was very different across countries, ranging from .3\% (Zimbabwe) to $5.2 \%$ (Rwanda) [22]. Thus the study countries reflect the incredible diversity of the African continent.

\section{Study questions}

The study seeks to answer two primary questions:

1. Does child mortality in Africa vary by birth order and by how much? 
Table 1 Number of children (Alive and Dead) for mothers interviewed in demographic and health surveys by country and survey year

\begin{tabular}{|c|c|c|c|c|c|c|c|}
\hline \multirow[b]{2}{*}{ Country } & \multicolumn{2}{|l|}{ Decade 1} & \multicolumn{2}{|l|}{ Decade 2} & \multicolumn{2}{|l|}{ Decade 3} & \multirow{2}{*}{$\begin{array}{l}\text { All Decades } \\
\text { Number of Children }\end{array}$} \\
\hline & Survey Year & Number of Children & Survey Year & Number of Children & Survey Year & Number of Children & \\
\hline Burkina Faso & 1993 & 20,655 & 2003 & 41,520 & 2010 & 56,178 & 118,353 \\
\hline Cameroon & 1991 & 11,612 & 2004 & 29,455 & 2011 & 42,312 & 83,379 \\
\hline Cote D'Ivoire & 1994 & 24,870 & 1998 & 7575 & 2011 & 28,211 & 60,656 \\
\hline Egypt & 1988 & 35,519 & 2000 & 54,780 & 2008 & 48,619 & 138,918 \\
\hline Ghana & 1988 & 14,216 & 1998 & 13,188 & 2008 & 11,888 & 39,292 \\
\hline Kenya & 1988 & 25,173 & 1999 & 23,351 & 2008 & 22,534 & 71,058 \\
\hline Madagascar & 1992 & 18,931 & 2000 & 20,799 & 2010 & 48,464 & 88,194 \\
\hline Malawi & 1992 & 16,330 & 2000 & 40,421 & 2010 & 72,301 & 129,052 \\
\hline Mali & 1987 & 12,251 & 2001 & 48,407 & $2012-13$ & 33,803 & 94,461 \\
\hline Namibia & 1992 & 13,372 & 2000 & 14,946 & 2013 & 18,090 & 46,408 \\
\hline Niger & 1992 & 23,841 & 1998 & 28,888 & 2012 & 44,183 & 96,912 \\
\hline Nigeria & 1990 & 28,123 & 2003 & 23,038 & 2013 & 119,386 & 170,547 \\
\hline Rwanda & 1992 & 19,440 & 2000 & 27,602 & 2010 & 32,639 & 79,681 \\
\hline Senegal & 1986 & 14,389 & 1997 & 27,448 & 2010-11 & 42,510 & 84,347 \\
\hline Tanzania & 1991-92 & 29,143 & 2004-05 & 30,557 & 2010 & 29,777 & 89,477 \\
\hline Uganda & 1988-89 & 16,074 & 2000-01 & 23,410 & 2011 & 28,609 & 68,093 \\
\hline Zambia & 1992 & 22,122 & 2001-02 & 23,805 & 2013 & 49,207 & 95,134 \\
\hline Zimbabwe & 1988 & 12,404 & 1999 & 14,184 & 2010-11 & 19,279 & 45,867 \\
\hline All Countries & & 358,465 & & 493,374 & & 747,990 & $1,599,829$ \\
\hline
\end{tabular}

Includes all children, before analytic sample restrictions

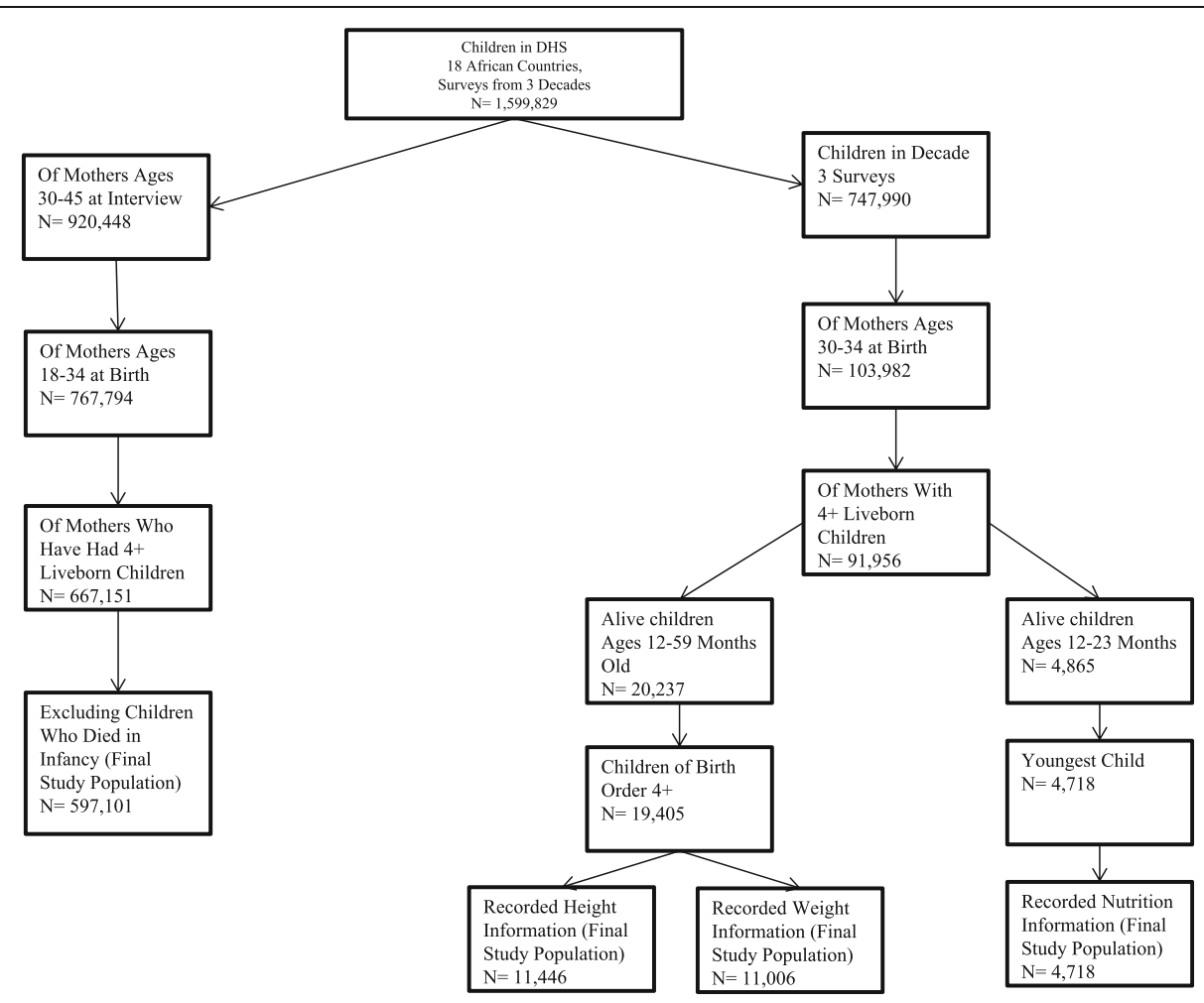

Fig. 1 Analytic Sample Definition 
2. Does child nutritional status in Africa vary by birth order and by how much?

Data have been added to the DHS through the years, so that nutritional status can be addressed only in the third decade round of surveys.

\section{Study groups}

Figure 1 shows the analysis sample selection. Since the focus of the study is on potential competition within a household for food and other resources, we study children of older mothers who have had four or more births. Further we exclude infants, because their mortality is strongly associated with the mother's health and the circumstances surrounding her prenatal, delivery, and post-partum health services. Their nutrition is primarily associated with breastfeeding, so they are not in competition with other children in the family for food until their second year. As shown in the figure, the sample size is much larger for the mortality analysis-since it spans three decades of surveys and all children of included mothers, in contrast to the nutrition analysis, which includes only the youngest children alive at the time of the third decade surveys.

\section{Mortality analysis}

The DHS interviews a nationally represented sample of mothers and asks about all the children they have had, including those who survived and those who died. Our mortality study group consists of all children of those mothers interviewed in the included years. Thus it includes children who were born (and died) across a wide range of dates (not, for example, reflecting child mortality in that country at the time of the interview). The study group is restricted to mothers who were between the ages of 18 and 34 at the time of the birth of their child (eliminating very early and very late births, in order to have greater comparability in the family circumstance and mother's health during the child's early years), as well as those who were between the ages of 30 and 44 at the time of the interview (to have the opportunity for all or most of her children, including the later births, to be included in the analysis). We examine mortality for two groups: children ages 1-4 and children ages 5-14 (not a group that is frequently studied). Because of age restrictions the rates presented do not track closely with published under 5 mortality rates. We benchmarked our data against those rates, using standard methods for calculating under- 5 mortality rates from the DHS, and the data track very closely.

Table 2 Trends in child mortality for children in large families by age group and decade in 18 African Countries

\begin{tabular}{|c|c|c|c|c|c|c|c|c|}
\hline & \multicolumn{4}{|c|}{ Deaths per 1000 Children Ages 1-4 } & \multicolumn{4}{|c|}{ Deaths per 1000 Children Ages 5-14 } \\
\hline & Before 1980 & 1980-1989 & 1990-1999 & $2000-2014$ & Before 1980 & 1980-1989 & 1990-1999 & $2000-2014$ \\
\hline Burkina Faso & 154 & 119 & 109 & 86 & 33 & 35 & 36 & 31 \\
\hline Cameroon & 99 & 63 & 67 & 68 & 24 & 28 & 32 & 30 \\
\hline Cote D'Ivoire & 85 & 61 & 61 & 46 & 22 & 24 & 32 & 26 \\
\hline Egypt & 98 & 41 & 19 & 7 & 21 & 8 & 8 & 5 \\
\hline Ghana & 88 & 72 & 52 & 33 & 40 & 24 & 20 & 19 \\
\hline Kenya & 49 & 33 & 37 & 29 & 18 & 11 & 16 & 13 \\
\hline Madagascar & 79 & 84 & 57 & 36 & 40 & 49 & 33 & 21 \\
\hline Malawi & 162 & 130 & 99 & 67 & 43 & 40 & 32 & 20 \\
\hline Mali & 206 & 160 & 117 & 54 & 62 & 36 & 37 & 25 \\
\hline Namibia & 36 & 29 & 23 & 24 & 10 & 14 & 14 & 16 \\
\hline Niger & 215 & 215 & 195 & 106 & 77 & 56 & 55 & 47 \\
\hline Nigeria & 134 & 116 & 117 & 84 & 50 & 29 & 40 & 24 \\
\hline Rwanda & 158 & 84 & 100 & 55 & 72 & 49 & 86 & 33 \\
\hline Senegal & 180 & 103 & 72 & 44 & 54 & 31 & 37 & 23 \\
\hline Tanzania & 87 & 67 & 64 & 37 & 18 & 23 & 21 & 15 \\
\hline Uganda & 86 & 84 & 71 & 51 & 52 & 28 & 25 & 22 \\
\hline Zambia & 87 & 79 & 76 & 43 & 28 & 22 & 28 & 16 \\
\hline Zimbabwe & 49 & 24 & 28 & 25 & 24 & 9 & 14 & 16 \\
\hline
\end{tabular}

Includes all children (regardless of year born) of mothers alive in survey year; restricted to children whose mothers were 18-34 at child's birth and were 30-44 years old at the time of interview, and to children in families with $4+$ children ever born to surveyed mothers. Methodology for mortality rate calculations adopted from Demographic and Health Surveys [28] 


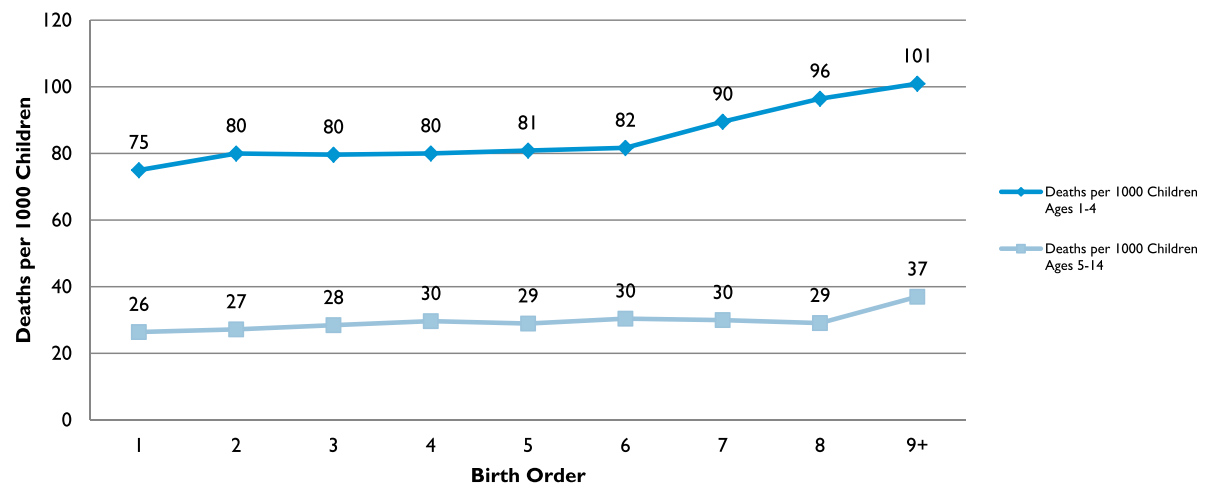

Fig. 2 Child Mortality by Age and Birth Order, Children in Large Families in 18 African Countries. Footnote: Includes all children (regardless of year born) of mothers alive in survey year; restricted to children whose mothers were 18-34 at child's birth and were 30-44 years old at the time of interview, and to children in families with $4+$ children ever born to surveyed mothers. Methodology adopted from Demographic Health Survey mortality rate calculations [28]

The analysis of mortality uses a Cox proportional hazards model [23] to estimate the mortality risk associated with birth order during ages $1-4$ and 5-14, for all children of mothers in the study. The model controls for country, child gender, child date of birth, mother's age at birth, mother's education, mother's marital status, and mother's intended family size. It also includes various household characteristics at the time of the survey, such as rurality, household size, and housing quality and sanitation. We enter birth order as a continuous variable; an alternative estimation using a quadratic specification yielded substantially similar results.

\section{Nutrition analysis}

The nutrition analysis uses a single round of data from the third decade surveys due to lack of data availability on nutrition measures in earlier DHS rounds. The analysis-limited to mothers ages $30-34$ at the time of the child's birth who have had at least 4 children-uses logistic regression to predict whether a child is stunted, low weight, consumed fewer than four food groups in the past $24 \mathrm{~h}$, or consumed any fruits and vegetables in that time period.

The first two nutrition outcomes are measures of a child's size, in particular whether the child was stunted or low weight. Children ages 12 to 59 months are included in the analysis. The child's size is compared to norms of the WHO, and stunted or low weight is 2 standard deviations below the norm [24]. Unfortunately, there is a high rate of missing data (see Fig. 1).

The other two nutrition measures are for children ages 12-23 months who are the youngest children in the household (a survey restriction). Among these children, the mother is asked what foods and liquids (other than breast milk) the child was fed in the past $24 \mathrm{~h}$. These are then categorized into six food groups, based on categories defined by the WHO: grains, roots and tubers; dairy products; legumes and nuts; flesh foods and eggs; vitamin A rich foods and vegetables; and other fruits and vegetables [25].

The control variables are the same as for the mortality analysis, with the addition of whether the mother breastfed the child in the past day. Instead of housing and water quality, the indicators of poverty used in the mortality analysis, we use the DHS "wealth index" which is a composite index of household poverty added in the last two survey rounds [26].

Table 3 Descriptive statistics for variables in cox proportional hazard model

\begin{tabular}{lll}
\hline & Mean & C.I. \\
\hline Child Characteristics: & 3.67 & {$[3.65,3.68]$} \\
$\quad$ Birth Order (continuous) & 0.51 & {$[0.50,0.51]$} \\
Male Child Gender & 90.03 & {$[89.88,90.18]$} \\
Child's Birth Date (In years since 1900) & & \\
Mother Characteristics: & 25.13 & {$[25.11,25.15]$} \\
Age at Child's Birth (continuous years) & 0.51 & {$[0.51,0.52]$} \\
No Formal Education & 0.10 & {$[0.09,0.10]$} \\
Not Married & 6.32 & {$[6.27,6.36]$} \\
Ideal Number of Children (continuous) & & \\
Household Characteristics: & 0.75 & {$[0.74,0.75]$} \\
$\quad$ Household located in Rural Area & 8.24 & {$[8.17,8.30]$} \\
Household Size & 0.53 & {$[0.52,0.54]$} \\
Natural (Unmodified) Flooring & 0.83 & {$[0.83,0.84]$} \\
No Flushable Toilet & 597,101 & \\
\hline
\end{tabular}

Note: Includes all children (regardless of year born) of mothers alive in survey year; restricted to children whose mothers were 18-34 at child's birth and were 30-44 years old at the time of interview, and to children in families with 4+ children ever born to surveyed mothers. Excludes children in infancy or who died in infancy. Maternal characteristics are at time of survey, except for age at child's birth 


\section{Results}

\section{Mortality analysis}

Table 2 shows mortality per 1000 for children ages $1-4$ and ages 5-14 by country and decade of the child's birth, for the mortality study population (see Fig. 1 for restrictions).
Mortality declined over time in both age groups, but at different rates per country, and not always monotonically. For example, between the 1980s and 1990s several countries experienced increased child mortality for the older age group, and the average across all countries did not decline for ages 5-14. The countries with

Table 4 Cox proportional hazards model for child mortality by age group

\begin{tabular}{|c|c|c|c|c|}
\hline & \multicolumn{2}{|l|}{ Ages 1-4 } & \multicolumn{2}{|l|}{ Ages 5-14 } \\
\hline & Hazard ratio & C.I. & Hazard ratio & C.I. \\
\hline Birth order (Continuous) & $1.13^{c}$ & {$[1.11,1.15]$} & $1.10^{c}$ & {$[1.07,1.13]$} \\
\hline \multicolumn{5}{|l|}{ Country: } \\
\hline Burkina Faso & $1.78^{c}$ & {$[1.60,1.98]$} & $2.58^{c}$ & {$[2.05,3.23]$} \\
\hline Cameroon & $1.34^{c}$ & {$[1.18,1.51]$} & $2.52^{c}$ & {$[1.98,3.19]$} \\
\hline Cote d'Ivoire & $1.18^{\mathrm{a}}$ & {$[1.02,1.36]$} & $2.32^{c}$ & {$[1.80,2.99]$} \\
\hline Egypt (reference) & 1.00 & - & 1.00 & - \\
\hline Ghana & 1.13 & {$[0.99,1.29]$} & $1.95^{\mathrm{c}}$ & {$[1.52,2.51]$} \\
\hline Kenya & $0.59^{c}$ & {$[0.51,0.68]$} & 1.11 & {$[0.85,1.45]$} \\
\hline Madagascar & $1.22^{\mathrm{b}}$ & {$[1.07,1.38]$} & $2.46^{\mathrm{C}}$ & {$[1.94,3.13]$} \\
\hline Malawi & $1.67^{c}$ & {$[1.50,1.86]$} & $2.12^{c}$ & {$[1.68,2.68]$} \\
\hline Mali & $1.68^{c}$ & {$[1.49,1.89]$} & $2.55^{\mathrm{c}}$ & {$[2.01,3.24]$} \\
\hline Namibia & $0.54^{c}$ & {$[0.46,0.63]$} & 1.25 & {$[0.95,1.66]$} \\
\hline Niger & $2.50^{c}$ & {$[2.23,2.80]$} & $3.71^{c}$ & {$[2.95,4.68]$} \\
\hline Nigeria & $2.08^{c}$ & {$[1.84,2.34]$} & $2.70^{c}$ & {$[2.15,3.41]$} \\
\hline Rwanda & $1.54^{c}$ & {$[1.37,1.73]$} & $4.85^{\mathrm{c}}$ & {$[3.83,6.12]$} \\
\hline Senegal & $2.06^{c}$ & {$[1.84,2.32]$} & $3.19^{c}$ & {$[2.49,4.08]$} \\
\hline Tanzania & 1.04 & {$[0.92,1.18]$} & $1.44^{\mathrm{b}}$ & {$[1.13,1.85]$} \\
\hline Uganda & 1.12 & {$[0.99,1.26]$} & $2.00^{c}$ & {$[1.58,2.55]$} \\
\hline Zambia & $1.43^{c}$ & {$[1.28,1.61]$} & $1.89^{c}$ & {$[1.50,2.39]$} \\
\hline Zimbabwe & $0.62^{c}$ & {$[0.53,0.72]$} & 1.23 & {$[0.94,1.61]$} \\
\hline \multicolumn{5}{|l|}{ Child Characteristics } \\
\hline Child Date of Birth (years since 1900) & $0.98^{c}$ & {$[0.98,0.98]$} & $0.98^{c}$ & {$[0.98,0.98]$} \\
\hline Child Gender ( 1 = male) & 1.03 & {$[0.99,1.07]$} & $1.08^{\mathrm{a}}$ & {$[1.00,1.17]$} \\
\hline \multicolumn{5}{|l|}{ Maternal Characteristics: } \\
\hline Age at Child's Birth (continuous) & $0.95^{\mathrm{c}}$ & {$[0.94,0.95]$} & $0.97^{c}$ & {$[0.96,0.99]$} \\
\hline No Formal Education & $1.48^{\mathrm{C}}$ & {$[1.41,1.56]$} & $1.29^{c}$ & {$[1.16,1.43]$} \\
\hline Not Married or Cohabiting & $0.89^{\mathrm{b}}$ & {$[0.83,0.96]$} & 1.02 & {$[0.91,1.15]$} \\
\hline Ideal Number of Children (continuous) & 0.99 & {$[0.98,1.00]$} & 0.99 & {$[0.98,1.01]$} \\
\hline \multicolumn{5}{|l|}{ Household Characteristics: } \\
\hline Number of Household Members (continuous) & $0.95^{c}$ & {$[0.95,0.96]$} & $0.96^{\mathrm{b}}$ & {$[0.94,0.99]$} \\
\hline Rural Resident & $1.19^{c}$ & {$[1.12,1.27]$} & $1.23^{c}$ & {$[1.10,1.37]$} \\
\hline Natural (Unmodified) Flooring & $1.39^{c}$ & {$[1.30,1.48]$} & $1.17^{\mathrm{b}}$ & {$[1.05,1.31]$} \\
\hline No Flushable Toilet & $1.59^{c}$ & {$[1.44,1.75]$} & $1.55^{\mathrm{c}}$ & {$[1.28,1.86]$} \\
\hline
\end{tabular}

Includes all children (regardless of year born) of mothers alive in survey year; restricted to children whose mothers were 18-34 at child's birth and were 30-44 years old at the time of interview, and to children in families with 4+ children ever born to surveyed mothers. Maternal characteristics are at time of survey except for age at child's birth ${ }^{\mathrm{a}}$ Significant at .05 level

${ }^{\mathrm{b}}$ Significant at .01 level

'Significant at .001 level 
increases include Nigeria, Rwanda (just following the genocide), and Zimbabwe (where poverty and HIV increased), reminders of how war and poverty contribute to lower child survival. Other countries that saw an increase in that period include several West African countries (Burkina Faso, Cameroon, and Cote D'Ivoire), suggesting this trend is not just a result of the HIV epidemic.

There is no MDG or SDG concerning child survival for school aged children, but it is evident from the figure that mortality in African countries is substantial for ages 5 to 14. For example, in the most recent period (2000-2014) in Ghana the mortality rate was 33 per 1000 among children ages $1-4$ in the study group, and 19 per 1000 for children 5-14.

Figure 2 shows mortality rates by age group and birth order. Mortality increases slowly for birth orders 1-6 for younger children and 1-8 for older children. Mortality then increases substantially for higher order children.

Table 3 shows means and confidence intervals for the control variables in the regressions. Average birth order is 3.7 across the entire study group. The children in the study are primarily those of mothers living in large, poor rural households.

Table 4 shows the Cox regression results for mortality by age group. The resulting hazards ratio is 1.13 for children ages $1-4$ and 1.10 for children ages $5-14$. This means that there is an average $13 \%$ increase in mortality risk, on average, for each increase in birth order. For example, a sixth child is $13 \%$ more likely to die than the fifth child. Most other factors in the model are significantly related to mortality. The exceptions are gender (for younger children) and the ideal number of children. The direction of the effects and the significance are substantially similar for both age groups. (Countries are compared to Egypt, which has the lowest mortality.)
Figure 3 shows the survival curves implied by the hazard analysis from ages 1 to 4 , by birth order, holding constant other factors. Figure 4 depicts similar data for older children. The figures highlight the clear relationship between survival and birth order. For example, there is about an 8 percentage point difference between the probability of survival from age 1 to age 5 for birth order 1 and birth order 9 children, and about a 2 percentage point difference in the survival probability from age 5 to age 14 .

The data from the models can also be used to show what share of deaths could have been avoided had all children had the mortality experience of those of birth orders $1-3$. We estimate that $33.7 \%$ of all deaths to young children (ages 1-4) with birth order greater than 3 would not have occurred if they had the mortality rates of children with birth order 3 or less. For older children (ages 5-14), this excess share of deaths associated with higher birth orders is $27.0 \%$.

\section{Nutrition analysis}

DHS data can also be used to illustrate that the mortality disparity by birth order may be due in part to competition for food within the family. Figure 5 shows the level of stunting and low weight for children ages 1259 months, by birth order. Before controlling for other factors there is a clear relationship between birth order and poor nutrition among children ages $12-59$. The rates rise from $34.3 \%$ stunted and $18.3 \%$ low weight for birth order 4 to $56.9 \%$ and $39.5 \%$ respectively for birth orders $9+$.

Table 5 shows logistic regression results predicting the odds of being stunted or low weight. As with mortality, after controlling for other factors, as birth order rises the odds are significantly higher that a child ages $12-59$ months will be stunted or low weight. However, the country effects are less often significant in the stunting

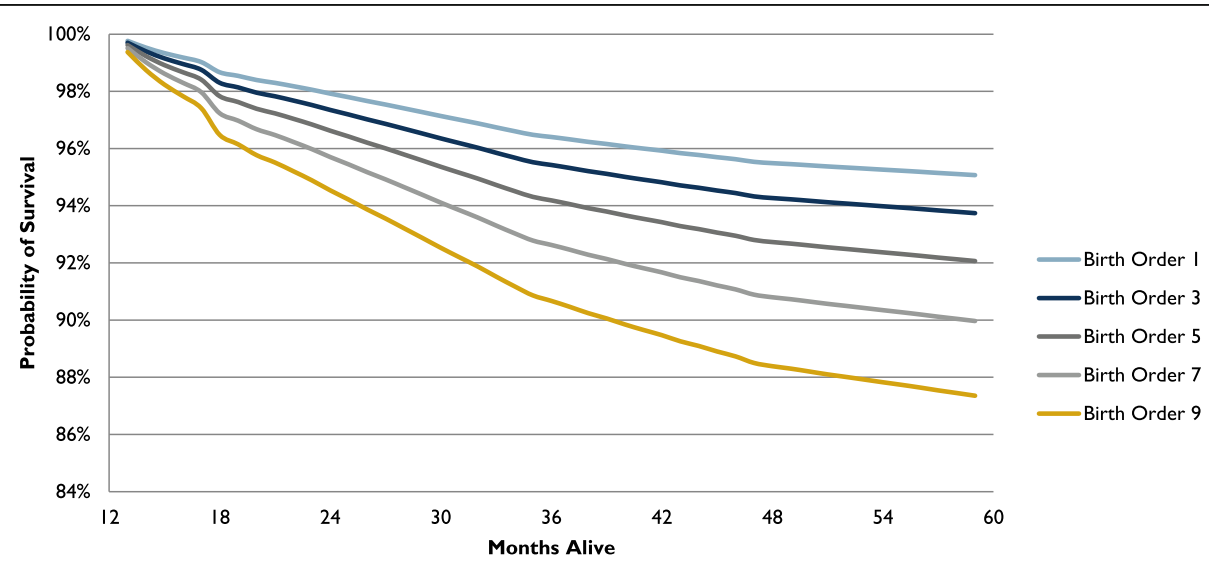

Fig. 3 Probability of Survival by Birth Order, Children Ages 1-4. Footnote: Includes all children (regardless of year born) of mothers alive in survey year; restricted to children whose mothers were 18-34 at child's birth and were 30-44 years old at the time of interview, and to children in families with 4+ children ever born to surveyed mothers. Methodology adopted from Demographic Health Survey mortality rate calculations [28] 


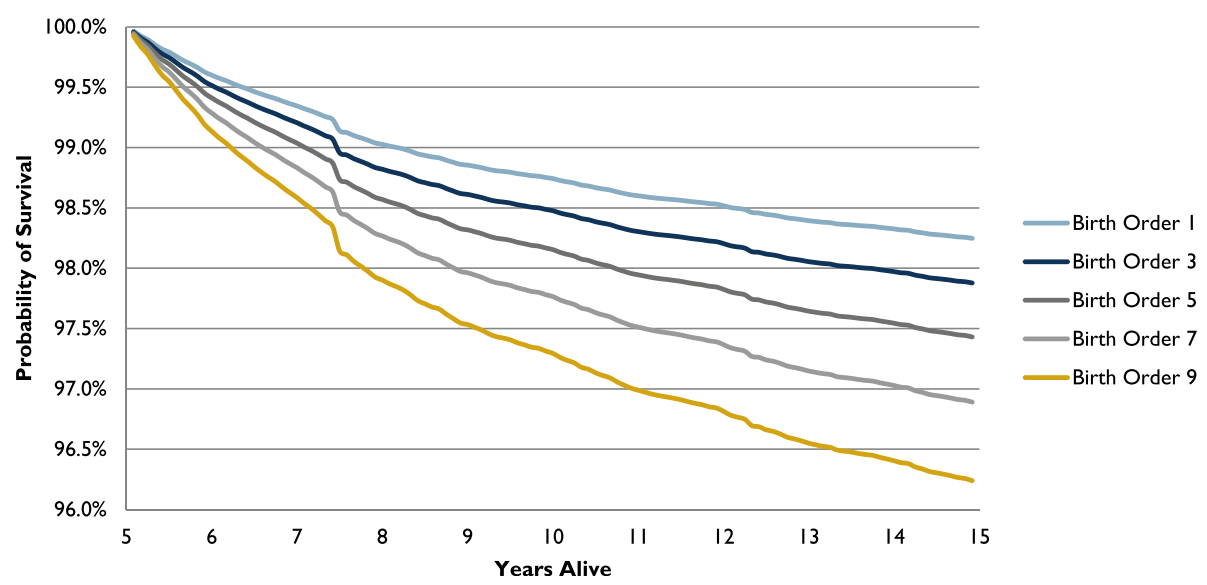

Fig. 4 Probability of Survival by Birth Order, Children Ages 5-14. Footnote: Includes all children (regardless of year born) of mothers alive in survey year; restricted to children whose mothers were 18-34 at child's birth and were 30-44 years old at the time of interview, and to children in families with 4+ children ever born to surveyed mothers. Methodology adopted from Demographic Health Survey mortality rate calculations [28]

model. Current breastfeeding is significantly related to being low weight, but not to stunting.

There is also a relationship between diet quality and birth order in study group children ages 12 to 23 months (Fig. 6). Higher birth order children consumed fewer different food groups in the $24 \mathrm{~h}$ before the survey and less often ate fruits and vegetables.

Table 6 shows logistic regression results for dietary quality. There is a significant relationship to birth order for both the odds of having eaten fewer than 4 food groups and to have eaten no fruits and vegetables in the past $24 \mathrm{~h}$. Therefore, higher birth order children have lower quality diets, using both measures, controlling for many other factors.

\section{Sensitivity analyses}

Two sensitivity analyses provide additional insights into these relationships. A quadratic (rather than linear) specification for birth order shows there is an even stronger relationship between birth order and mortality at the highest birth orders. To investigate the extent to which our findings are driven by certain countries, we tested the interaction between birth order and country. Results show that-except for mortality for ages 1-4 where the relationship is highly significant in all countries-there is not always a statistically significant relationship between mortality or nutritional status and birth order in every country. This is likely due to variation in effects across countries, as well as smaller sample sizes (see Table 7).

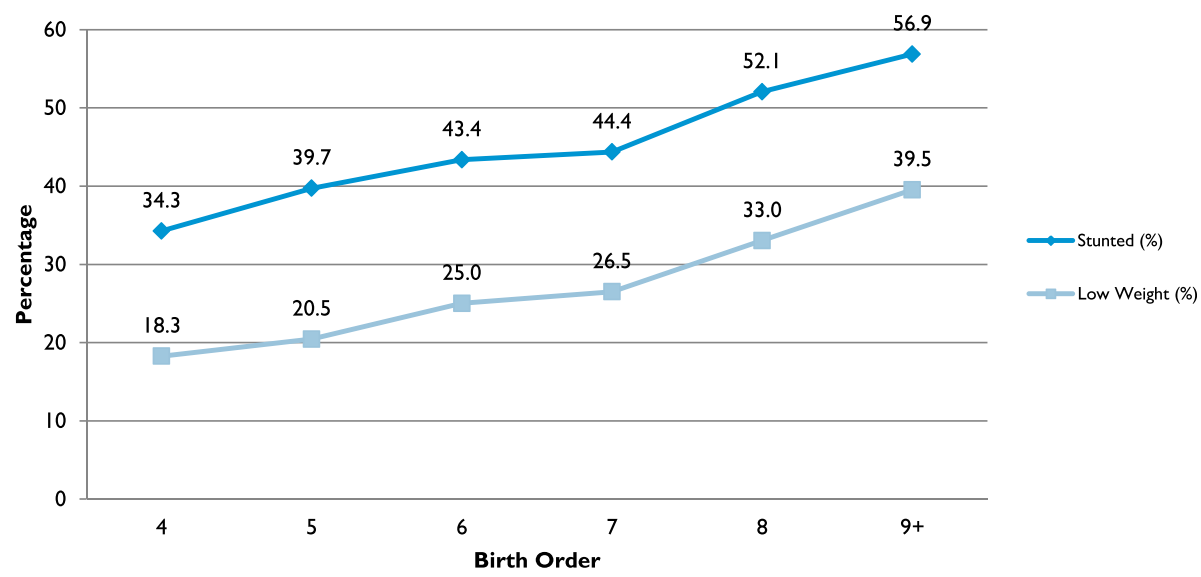

Fig. 5 Stunted or Low Weight by Birth Order, Children Ages 12-59 Months. Footnote: Restricted to children ages 12-59 months and a 4+ birth order, whose mothers were 30-34 at child's birth. Maternal characteristics are at time of survey except for age at child's birth. Stunted is defined as a height for age below minus two standard deviations from an established WHO reference mean; Low Weight is defined as a weight for age below minus two standard deviations from an established WHO reference mean [24, 29] 
Table 5 Logistic regression model predicting stunting and low weight children ages 12-59 months

\begin{tabular}{|c|c|c|c|c|}
\hline & \multicolumn{2}{|l|}{ Stunted } & \multicolumn{2}{|l|}{ Low weight } \\
\hline & Odds ratio & 95 \% C.I. & Odds ratio & 95 \% C.I. \\
\hline Birth Order (Continuous) & $1.08^{\mathrm{c}}$ & {$[1.04,1.13]$} & $1.06^{\mathrm{a}}$ & {$[1.00,1.11]$} \\
\hline \multicolumn{5}{|l|}{ Country: } \\
\hline Burkina Faso & 1.29 & {$[0.98,1.69]$} & $5.06^{c}$ & {$[3.22,7.95]$} \\
\hline Cameroon & 1.01 & {$[0.71,1.43]$} & $2.86^{\mathrm{C}}$ & {$[1.69,4.83]$} \\
\hline Cote d'Ivoire & 0.81 & {$[0.57,1.17]$} & $2.15^{\mathrm{b}}$ & {$[1.22,3.79]$} \\
\hline Egypt (reference) & 1.00 & - & 1.00 & - \\
\hline Ghana & 0.76 & {$[0.52,1.12]$} & $2.68^{c}$ & {$[1.51,4.75]$} \\
\hline Kenya & $1.74^{\mathrm{b}}$ & {$[1.22,2.50]$} & $6.09^{c}$ & {$[3.61,10.29]$} \\
\hline Madagascar & $2.65^{c}$ & {$[1.88,3.73]$} & . & \\
\hline Malawi & $2.14^{\mathrm{c}}$ & {$[1.54,2.97]$} & $2.62^{c}$ & {$[1.49,4.60]$} \\
\hline Mali & 1.25 & {$[0.90,1.75]$} & $4.38^{c}$ & {$[2.67,7.20]$} \\
\hline Namibia & 0.72 & {$[0.44,1.19]$} & $3.33^{c}$ & {$[1.64,6.75]$} \\
\hline Niger & 1.14 & {$[0.83,1.58]$} & $6.26^{c}$ & {$[3.83,10.23]$} \\
\hline Nigeria & 1.26 & {$[0.98,1.62]$} & $6.64^{c}$ & {$[4.30,10.26]$} \\
\hline Rwanda & $2.46^{c}$ & {$[1.83,3.31]$} & $3.35^{c}$ & {$[2.03,5.52]$} \\
\hline Senegal & 0.84 & {$[0.58,1.20]$} & $2.97^{\mathrm{C}}$ & {$[1.75,5.03]$} \\
\hline Tanzania & $2.13^{\mathrm{c}}$ & {$[1.61,2.82]$} & $4.10^{c}$ & {$[2.52,6.67]$} \\
\hline Uganda & 1.21 & {$[0.83,1.78]$} & $2.82^{c}$ & {$[1.58,5.03]$} \\
\hline Zambia & $1.49^{b}$ & {$[1.15,1.94]$} & $3.03^{\mathrm{c}}$ & {$[1.91,4.79]$} \\
\hline Zimbabwe & 1.34 & {$[0.96,1.87]$} & $2.97^{c}$ & {$[1.69,5.23]$} \\
\hline \multicolumn{5}{|l|}{ Child Characteristics: } \\
\hline Male Child Gender & $1.22^{\mathrm{c}}$ & {$[1.09,1.36]$} & 1.14 & {$[1.00,1.31]$} \\
\hline Child Currently Being Breastfed & 0.97 & {$[0.82,1.16]$} & $1.31^{\mathrm{a}}$ & {$[1.05,1.62]$} \\
\hline Child's Current Age (Months) & 0.995 & {$[0.99,1.00]$} & 0.9996 & {$[0.99,1.01]$} \\
\hline \multicolumn{5}{|l|}{ Maternal Characteristics: } \\
\hline Age at Child's Birth (continuous) & 1.02 & {$[0.98,1.06]$} & 1.04 & {$[0.99,1.09]$} \\
\hline No Formal Education & $1.18^{\mathrm{a}}$ & {$[1.02,1.36]$} & $1.48^{\mathrm{c}}$ & {$[1.23,1.78]$} \\
\hline Not Married or Cohabiting & 0.93 & {$[0.74,1.18]$} & 1.24 & {$[0.86,1.79]$} \\
\hline Ideal Number of Children (continuous) & $1.03^{b}$ & {$[1.01,1.06]$} & $1.05^{c}$ & {$[1.02,1.08]$} \\
\hline \multicolumn{5}{|l|}{ Household Characteristics: } \\
\hline Number of Household Members (continuous) & 1.01 & {$[0.99,1.03]$} & 1.02 & {$[1.00,1.04]$} \\
\hline Rural Resident & $1.27^{\mathrm{b}}$ & {$[1.07,1.50]$} & 0.87 & {$[0.71,1.08]$} \\
\hline Poor or Poorest (Wealth Index) & $1.67^{c}$ & {$[1.47,1.91]$} & $1.65^{c}$ & {$[1.40,1.95]$} \\
\hline
\end{tabular}

Restricted to children ages 12-59 months and a 4+ birth order, whose mothers were 30-34 at child's birth. Maternal characteristics are at time of survey except for age at child's birth. Stunted is defined as a height for age below two standard deviations from an established WHO reference mean; Low Weight is defined as a weight for age below two standard deviations from an established WHO reference mean. See http://www.who.int/childgrowth/en/ and http://www.unicef.org/ infobycountry/stats_popup2.html for more information

${ }^{a}$ Significant at .05 level

bSignificant at .01 level

'Significant at .001 level

\section{Discussion}

Data from Africa spanning several decades show that, on average and for larger families, birth order is strongly related to mortality for the youngest children (ages 1-4) and for older children (ages 5-14) after controlling for a large number of factors including country; maternal age at birth and education; desired family size; rural residence; and poverty. Higher birth order children also are more often stunted and low weight, and receive less high quality food when they are very young.

This birth order effect has not been studied specifically for African countries and over such as long time period. 


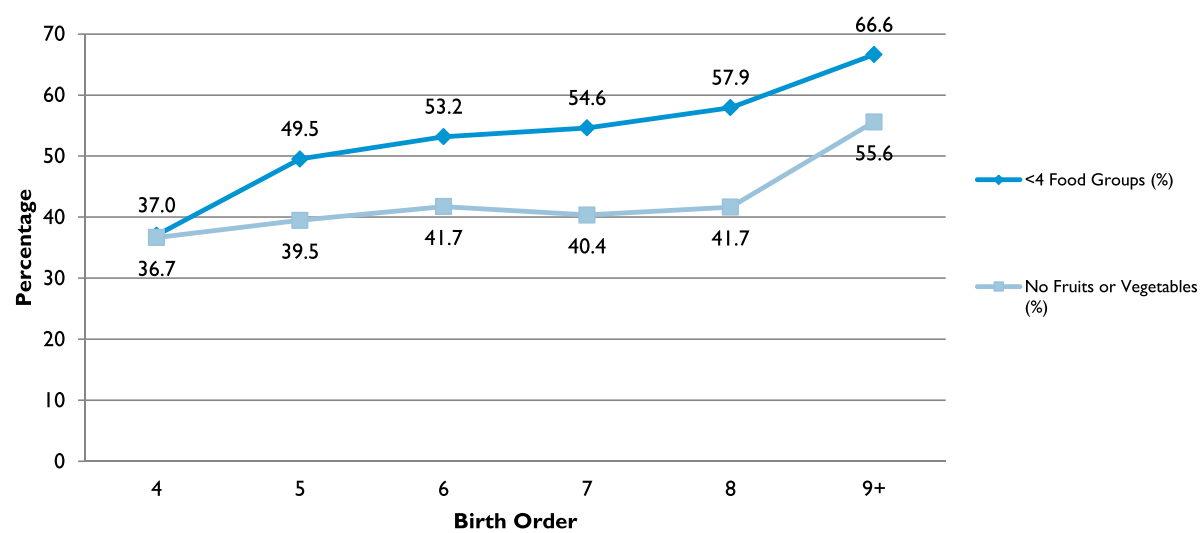

Fig. 6 Dietary Diversity and Consumption of Fruits/Negetables by Birth Order, Youngest Child 12-23 Months. Footnote: Includes youngest child of mothers alive in survey year with a child ages 12-23 months; restricted to children in families with 4+ children ever born to surveyed mothers and whose mothers were 30-34 years old at child's birth. Maternal characteristics are at time of survey except for age at child's birth. Dietary Diversity is defined as consuming food from fewer than 4 categories in the past $24 \mathrm{~h}$; Consumption of Fruits and Vegetables is defined as not consuming fruits or vegetables in the past $24 \mathrm{~h}$. Both indicators are reported by mother for her youngest child

Nor has child mortality been studied for older (schoolaged children); this study highlights that mortality for this older group is also high and increases with birth order. Thus the effects of birth order are not restricted to the earliest years (at least in some of the countries studied). In addition, this study highlights the potential role of nutrition differentials within the family during the early years that likely contribute to the mortality differentials.

While the data show a relationship between birth order, child mortality, and nutrition in Africa, there are several caveats to the analysis. We have shown a correlation between birth order and mortality, suggesting causation. However, there are many other potential determinants, but for which we have no data. In addition, there are factors that are included that are related to both birth order and to mortality or nutrition, such as poverty measures, leading to biased results. (Other important variables, such as total fertility and child spacing, are excluded from the model for this reason.) In addition, findings presented here represent an average across 18 countries; some countries such as Egypt and Nigeria are large. Country-specific analysis yields different results for some measures in some countries. The strongest and most consistent effects are for mortality ages $1-4$.

\section{Conclusions}

To the extent that we have successfully controlled for confounding factors that also affect mortality and nutrition, these data give a greater impetus to the Family Planning 2020 movement [27], which is sponsored by a large number of countries (including 16 of the study countries), and other large donors. The movement's goal is to assure access to high quality family planning to all women worldwide. More public education for families, health providers, and policy makers on the health risks for later born children in large families likely will provide greater incentives to encourage effective contraception use and to target nutrition interventions.

\section{Abbreviations}

DHS: Demographic and Health Surveys; MDGs: Millennium Development Goals; SDGs: Sustainable Development Goals; USAID: United States Agency for International Development

\section{Acknowledgements}

We acknowledge the Urban Institute for providing internal funding for the research and the Demographic and Health Survey program for providing data. We appreciate the advice of Shiela Isanaka, Sc.D., of the Department of Nutrition, Harvard School of Public Health, concerning the coding of dietary diversity for children. We received very helpful comments from Genevieve Kenney, Ph.D., Urban Institute, and Rachel Silverman, M. Phil., Center for Global Development, on an earlier draft of the paper.

\section{Funding}

Our sole source of funding for this project is an internal grant awarded to us by the Urban Institute.

\section{Availability of data and materials \\ The datasets supporting the conclusions of this article are publicly available for download at http://dhsprogram.com/Data/.}

\section{Authors' contributions}

EH_Primary Investigator/Writing. NH_Programming/Quantitative Analysis. TW-Quantitative Methods. All authors read and approved the final manuscript.

\section{Authors' information}

Embry Howell (Ph.D. in Public Policy, George Washington University; MSPH in Biostatistics, University of North Carolina) is a Senior Fellow in the Health

Policy Center at the Urban Institute in Washington, D.C. Her research focuses on maternal and child health outcomes and policy. She has conducted studies of birth outcomes in the U.S. and abroad, and has studied maternal and child health programs in Tanzania and South Africa.

Nikhil Holla is a current medical student at George Washington University. Previously, as a research assistant at the Urban Institute in the Health Policy Center, he provided quantitative and qualitative analysis for a variety of different health policy and interdisciplinary studies. His research focused on the social determinants of health of low income children and mothers, including projects on nutrition, prenatal care, and early childhood education. 
Table 6 Logistic regression model predicting dietary diversity and consumption of fruits/vegetables for children 12-23 months

\begin{tabular}{|c|c|c|c|c|}
\hline & \multicolumn{2}{|c|}{ Lack of Dietary Diversity (Less than 4 Food Groups) } & \multicolumn{2}{|c|}{ No Fruits or Vegetables } \\
\hline & Odds ratio & $95 \%$ C.I. & Odds ratio & $95 \%$ C.I. \\
\hline Birth Order (Continuous) & $1.11^{\mathrm{a}}$ & {$[1.02,1.22]$} & $1.09^{\mathrm{a}}$ & {$[1.02,1.17]$} \\
\hline \multicolumn{5}{|l|}{ Country: } \\
\hline Burkina Faso & $30.34^{c}$ & {$[14.29,64.42]$} & $2.53^{c}$ & {$[1.60,3.99]$} \\
\hline Cameroon & $2.31^{\mathrm{b}}$ & {$[1.35,3.92]$} & $0.52^{\mathrm{b}}$ & {$[0.31,0.85]$} \\
\hline Cote d'Ivoire & $9.25^{c}$ & {$[4.36,19.62]$} & $2.95^{\mathrm{C}}$ & {$[1.64,5.29]$} \\
\hline Egypt (reference) & 1.00 & - & 1.00 & - \\
\hline Ghana & 1.11 & {$[0.56,2.20]$} & $0.23^{c}$ & {$[0.10,0.52]$} \\
\hline Kenya & $2.59^{\mathrm{a}}$ & {$[1.24,5.38]$} & $0.29^{c}$ & {$[0.14,0.61]$} \\
\hline Madagascar & $3.13^{c}$ & {$[1.74,5.63]$} & $0.31^{c}$ & {$[0.18,0.55]$} \\
\hline Malawi & $3.32^{c}$ & {$[2.00,5.51]$} & $0.32^{c}$ & {$[0.20,0.52]$} \\
\hline Mali & $3.49^{c}$ & {$[1.98,6.16]$} & 1.51 & {$[0.91,2.52]$} \\
\hline Namibia & $5.19^{c}$ & {$[2.55,10.58]$} & 1.63 & {$[0.86,3.09]$} \\
\hline Niger & $7.07^{c}$ & {$[3.80,13.16]$} & 1.54 & {$[0.90,2.61]$} \\
\hline Nigeria & $4.73^{c}$ & {$[2.90,7.70]$} & 1.17 & {$[0.76,1.79]$} \\
\hline Rwanda & $2.67^{c}$ & {$[1.60,4.45]$} & $0.37^{c}$ & {$[0.22,0.61]$} \\
\hline Senegal & $4.74^{\mathrm{c}}$ & {$[2.56,8.75]$} & 1.26 & {$[0.76,2.09]$} \\
\hline Tanzania & $9.70^{c}$ & {$[4.67,20.16]$} & $0.39^{b}$ & {$[0.22,0.68]$} \\
\hline Uganda & $11.07^{\mathrm{c}}$ & {$[5.26,23.31]$} & $0.29^{c}$ & {$[0.17,0.50]$} \\
\hline Zambia & $5.08^{c}$ & {$[2.95,8.78]$} & $0.37^{c}$ & {$[0.23,0.61]$} \\
\hline Zimbabwe & $5.16^{\mathrm{c}}$ & {$[2.33,11.41]$} & 0.63 & {$[0.33,1.19]$} \\
\hline \multicolumn{5}{|l|}{ Child Characteristics: } \\
\hline Male Child Gender & 1.07 & {$[0.86,1.33]$} & 1.09 & {$[0.90,1.31]$} \\
\hline Child Currently Being Breastfed & $1.69^{c}$ & {$[1.29,2.21]$} & 1.16 & {$[0.91,1.47]$} \\
\hline Child's Current Age (continuous) & 1.02 & {$[0.98,1.05]$} & $0.97^{\mathrm{a}}$ & {$[0.94,1.00]$} \\
\hline \multicolumn{5}{|l|}{ Maternal Characteristics: } \\
\hline Age at Child's Birth (continuous) & 0.96 & {$[0.88,1.04]$} & 0.97 & {$[0.91,1.03]$} \\
\hline No Formal Education & 1.23 & {$[0.91,1.67]$} & 1.17 & {$[0.93,1.47]$} \\
\hline Not Married or Cohabiting & 0.91 & {$[0.46,1.79]$} & 1.38 & {$[0.86,2.21]$} \\
\hline Ideal Number of Children (continuous) & 0.99 & {$[0.94,1.04]$} & 0.99 & {$[0.95,1.03]$} \\
\hline \multicolumn{5}{|l|}{ Household Characteristics: } \\
\hline Number of Household Members (continuous) & $0.96^{\mathrm{b}}$ & {$[0.93,0.99]$} & $0.97^{\mathrm{b}}$ & {$[0.94,0.99]$} \\
\hline Rural Resident & 1.25 & {$[0.92,1.69]$} & 1.06 & {$[0.82,1.38]$} \\
\hline Poor or Poorest (Wealth Index) & $1.73^{\mathrm{C}}$ & {$[1.32,2.26]$} & 1.07 & {$[0.86,1.33]$} \\
\hline
\end{tabular}

Includes youngest child of mothers alive in survey year with a child ages 12-23 months; restricted to children in families with 4+ children ever born to surveyed mothers and whose mothers were 30-34 years old at child's birth. Maternal characteristics are at time of survey except for age at child's birth. Dietary Diversity is defined as consuming food from fewer than 4 categories in the past $24 \mathrm{~h}$; Consumption of Fruits and Vegetables is defined as not consuming fruits or vegetables in the past $24 \mathrm{~h}$. Both indicators are reported by mother for her youngest child ${ }^{\mathrm{a}}$ Significant at .05 level

${ }^{\mathrm{b}}$ Significant at .01 level

'Significant at .001 level

Timothy Waidmann (Ph.D. in Economics, University of Michigan) is a health economist with over 20 years of experience designing and conducting studies in a variety of health policy topics including disability and health among the elderly; Medicare and Medicaid policy; disability and employment; public health and prevention; and health status and access to health care in vulnerable populations. He also has authored a set of empirical studies in demography and social epidemiology examining health and mortality disadvantage among low income populations in the United States.

Competing interests

The authors declare that they have no competing interests. 
Table 7 Statistically significant relationships between birth order and outcomes by country

\begin{tabular}{lll}
\hline Outcome & $\begin{array}{l}\text { Number of Countries with Significant } \\
\text { Relationship between Birth Order and Outcome }\end{array}$ & $\begin{array}{l}\text { Range of P-Values for Significant } \\
\text { Relationships }\end{array}$ \\
\hline $\begin{array}{l}\text { Mortality, } \\
\text { Ages 1-4 }\end{array}$ & All 18 countries & $P<.001$ for all countries \\
Mortality, & 8 (Cameroon, Cote d'Ivoire, Kenya, Madagascar, Mali, Niger, Nigeria, Senegal) & $.001-.050$ \\
Ages 5-14 & 2 (Nigeria, Uganda) & $.002-.044$ \\
Stunting & 2 (Cameroon, Nigeria) & $.028-.030$ \\
Low Weight & 4 (Burkina Faso, Kenya, Madagascar, Nigeria) & $.018-.045$ \\
Dietary Diversity & 3 (Ghana, Madagascar, Zimbabwe) & $.020-.037$ \\
No Fruits or Vegetables Consumed &
\end{tabular}

\section{Consent for publication}

Not Applicable.

\section{Ethics approval and consent to participate}

Not applicable.

\section{Author details}

${ }^{1}$ The Urban Institute, $2100 \mathrm{M}$ Street NW, Washington, DC, USA. ${ }^{2}$ George Washington University, Washington, DC, USA.

\section{Received: 3 June 2016 Accepted: 14 September 2016}

\section{Published online: 29 September 2016}

\section{References}

1. United Nations Millennium Declaration [Internet]. United Nations; 2000 Sep. Available from: http://www.un.org/millennium/declaration/ares552e.pdf. Accessed 17 Sept 2016.

2. You D, Hug L, Ejdemyr S, Idele P, Hogan D, Mathers C, et al. Global, regional, and national levels and trends in under-5 mortality between 1990 and 2015, with scenario-based projections to 2030: a systematic analysis by the UN Inter-agency Group for Child Mortality Estimation. Lancet. 2015;386:2275-86.

3. Sustainable Development Topics [Internet]. Sustain. Dev. Knowl. Platf. [cited 2016 Mar 18]. Available from: https://sustainabledevelopment.un.org/topics.

4. Independent Expert Review Group on Information and Accountability for Women's and Children's Health. Every woman, every child, every adolescent: achievements and prospects. Luxembourg: World Health Organization; 2015

5. 2015 World Population Data Sheet [Internet]. Population Reference Bureau; 2015 [cited 2016 Mar 18]. Available from: http://www.prb.org/pdf15/2015world-population-data-sheet_eng.pdf.

6. Rutstein SO. Factors associated with trends in infant and child mortality in developing countries during the 1990s. Bull World Health Organ. 2000;78:1256-70.

7. Ruth SR, Puffer CV. Birthweight, maternal age, and birth order: three important determinants in Infant Mortality. Washington, D.C: Pan American Health Organization; 1975.

8. Modin B. Birth order and mortality: a life-long follow-up of 14,200 boys and girls born in early 20th century Sweden. Soc Sci Med. 2002;54:1051-64. 1982.

9. Singh R, Tripathi V. Under-five mortality among mothers employed in agriculture: findings from a nationally representative sample. PeerJ. 2015;3:e710.

10. Rutstein SO, Winter R. The effects of fertility behavior on child survival and child nutritional status: Evidence from the Demographic and Health Surveys, 2006-2012 [Internet]. Rockville: ICF International; 2014. Available from: http://dhsprogram.com/pubs/pdf/AS37/AS37.pdf.

11. Hong $R$, Hor D. Factors associated with the decline of under-five mortality in Cambodia, 2000-2010: Further analysis of the Cambodia Demographic and Health Surveys [Internet]. Calverton: ICF International; 2013. Available from: http://dhsprogram.com/pubs/pdf/FA84/FA84.pdf.

12. Lawoyin TO. Risk factors for infant mortality in a rural community in Nigeria. J R Soc Promot Health. 2001;121:114-8.

13. Kozuki N, Sonneveldt E, Walker N. Residual confounding explains the association between high parity and child mortality. BMC Public Health. 2013;13:1-8.
14. Black SE, Devereux PJ, Salvanes KG. The more the merrier? The effect of family size and birth order on children's education. Q J Econ. 2005;120:669-700.

15. Sonneveldt E, DeCormier Plosky W, Stover J. Linking high parity and maternal and child mortality: what is the impact of lower health services coverage among higher order births? BMC Public Health. 2013;13:1-8.

16. Horton S. Birth order and child nutritional status: evidence from the Philippines. Econ Dev Cult Change. 1988:36:341-54.

17. The DHS Program: Demographic and Health Surveys [Internet]. [cited 2016 Mar 18]. Available from: http://www.dhsprogram.com/

18. International Data Base [Internet]. U. S. Census Bur. [cited 2016 Mar 18]. Available from: https://www.census.gov/population/international/data/idb/ informationGateway.php.

19. World Economic Outlook Database [Internet]. Int. Monet. Fund. [cited 2016 Mar 18]. Available from: https://www.imf.org/external/pubs/ft/weo/2015/01/ weodata/weorept.aspx?sy=2013\&ey=2020\&scsm=1\&ssd=1\&sort=country\& $\mathrm{ds}=. \& b r=1 \& \mathrm{c}=674 \% 2 \mathrm{C} 676 \% 2 \mathrm{C} 748 \% 2 \mathrm{C} 678 \% 2 \mathrm{C} 622 \% 2 \mathrm{C} 728 \% 2 \mathrm{C} 692 \% 2 \mathrm{C} 694 \%$ 2C714\%2C722\%2C662\%2C733\%2C648\%2C738\%2C652\%2C746\%2C754\%2C $664 \% 2 C 698 \& s=P P P P C \& g r p=0 \& a=\& p r$.

20. Murray CJL, Barber RM, Foreman KJ, Ozgoren AA, Abd-Allah F, Abera SF, et al. Global, regional, and national disability-adjusted life years (DALYs) for 306 diseases and injuries and healthy life expectancy (HALE) for 188 countries, 1990-2013: quantifying the epidemiological transition. Lancet. 2015;386: 2145-91.

21. Global Health Observatory Data Repository: HIV AIDS Statistical Tables [Internet]. Unicef. 2016 [cited 2016 Mar 18]. Available from: http://data.unicef.org/hiv-aids/global-trends.html.

22. Level \& Trends in Child Mortality [Internet]. New York: Unicef; 2015 Sep. Available from: http://www.childmortality.org/files_v20/download/ IGME\%20report\%202015\%20child\%20mortality\%20final.pdf. Accessed 17 Sept 2016.

23. Cox DR. Regression models and life-tables. J R Stat Soc Ser B Methodol. 1972;34:187-220.

24. The WHO Child Growth Standards [Internet]. World Health Organ. [cited 2016 Mar 18]. Available from: http://www.who.int/childgrowth/en/.

25. Indicators for Assessing Infant and Young Child Feeding Practices [Internet]. Washington, D.C.: World Health Organization; 2008. Available from: http://apps.who.int/iris/bitstream/10665/43895/1/9789241596664_eng.pdf. Accessed 17 Sept 2016.

26. Wealth Index [Internet]. DHS Program Demogr. Health Surv. 2016 [cited 2016 Mar 18]. Available from: http://www.dhsprogram.com/topics/wealthindex/Index.cfm.

27. FP2020 [Internet]. Fam. Plan. 2020. [cited 2016 Mar 18]. Available from: http://www.familyplanning2020.org/.

28. Infant and Child Mortality [Internet]. DHS Program. [cited 2016 Mar 13]. Available from: http://dhsprogram.com/Topics/Infant-and-Child-Mortality.cfm.

29. Definitions - Nutrition [Internet]. Unicef. [cited 2016 Apr 27]. Available from: http://www.unicef.org/infobycountry/stats_popup2.html. 